\title{
Recent trends in insecticide resistance research on whiteflies (Hemiptera: Aleyrodidae): a bibliometric profile
}

\author{
S. Rajna, K. V. Praveen*, M. Laneesha and S. S. Kelageri
}

This study is a bibliometric analysis of insecticide resistance research on whitefly carried out globally from 2010 to 2020. The analysis is based on 1198 research articles identified using Web of Science tool, which is processed further using VOSviewer. The results show that there is an increase in the number of articles, particularly from countries like USA and China. Denholm Ian, Liu Shu-Sheng and Xie Wen are identified as the most influential authors, and the Chinese Academy of Agricultural Sciences and Beijing Academy of Agriculture and Forestry Science in China, and the University of Florida and the University of Arizona in USA as key organizations. A total of 198 articles published during this period are highly cited. Pest Management Science and PLOS ONE are the important journals identified. The most common area of the research focus has been on the insecticide resistance of different whitefly species, and the status of resistance against different insecticide compounds. Our findings can act as a useful reference for researchers, and provide insights for directing future research on whitefly insecticide resistance that has potential implications for farming across the world.

Keywords: Bibliometric analysis, emerging trends, insecticide resistance, journal impact factor, research articles, whitefly.

WHITEFLIES are hemipterous insects under the family Aleyrodidae ${ }^{1}$. There are 1660 species of whiteflies across the world ${ }^{2}$. The economically important genes belonging to this family are Aleurodicus, Aleurodes, Bemisia, Dialeurodes, Trialeurodes, etc. ${ }^{3}$. Both adults and immature stages of whiteflies suck sap from the plants and reduce their vigour, causing yellowing and premature leaf fall. Besides, they secrete a large amount of honeydew triggering the development of black sooty mould which hinders photosynthesis. They also transmit different types of plant pathogenic viruses ${ }^{4}$. Though whiteflies are widely prevalent in warm to hot climates between $30^{\circ} \mathrm{N}$ and $\mathrm{S}$ of the equator ${ }^{5}$, their presence is confirmed in all continents, except Antarctica ${ }^{6}$.

The most worrying fact about whiteflies is their highly polyphagous nature and wide host range spread across 100 families of plants, including Malvaceae, Solanaceae, Arecaceae, Asteraceae, Brassicaceae, Cucurbitaceae, Leguminosae, Fabaceae, Euphorbiaceae, etc. ${ }^{7}$. The high number of generations per year, availability of alternate hosts, presence of wax and abaxial surface habitat of whi-

The authors are in the ICAR-Indian Agricultural Research Institute, New Delhi 110 012, India.

*For correspondence. (e-mail: veenkv@gmail.com) teflies make them difficult to manage effectively ${ }^{8}$. These characteristics triggered the indiscriminate use of insecticides in the farmers' fields to control whiteflies, which in turn resulted in the development of a high level of insecticide resistance ${ }^{9}$. According to the Arthropod Pesticide Resistance Database (APRD, 2020), among the sucking insects, the Aleyrodidae have the highest number of reported insecticide resistance cases (811). Bemisia tabaci (664), Trialeurodes vapourarium (112), Bemisia argentifolii (22), Aleurodes proletella (6), Dialeurodes citri (3), Trialeurodes albutilonea (3) and Aleurothrixus floccosus (1) are the species listed in APRD for insecticide resistance $^{10}$.

Resistance monitoring is a crucial research topic across the world since it is fundamentally important to any resistance management programme. Continuous monitoring of the populations for changes in resistance frequencies is necessary to make any decisions regarding effective management strategies ${ }^{11}$. Scientific publications providing evidence on topics including insecticide resistance status of whiteflies, cross-resistance development and the biochemical mechanisms involved, the role of different biotypes in resistance development, etc. have drawn the attention of researchers globally. This has triggered a huge volume of publications every year. Hence it 
becomes important to track the recent research trends on whitefly resistance and identify the key contributors to efficiently organize the results and evidence. Considering the vast and evolving literature on the insecticide resistance of whiteflies, here we provide a bibliometric analysis on the topic. The objective is to map the intellectual landscape of recent research and identify key articles, authors, organizations and countries contributing to it, and also track the emerging trends in research.

\section{Data and methods}

Bibliometric analysis is a useful method to extract information from research studies that are not directly reported in individual research and review articles ${ }^{12}$. For this study, a literature search on whitefly resistance for bibliometric analysis was done using the Web of Science (WoS) in December 2020. We targeted to identify only the articles (other document types were excluded) published in English between 2010 and 2020. To retrieve studies dealing with the insecticide resistance of whiteflies, we used the search specifications: ('Whitefly' or 'Bemisia tabaci' or 'Trialeurodes vaporariorum' or 'Bemisia argentifolii') and ('resistance'), applied to the title, abstract, author keyword, and topic fields, which resulted in 1198 studies after excluding the duplications. The bibliometric details regarding authors, year of publication, journal, title of the article, citations, etc. of all the retrieved studies were collected. Our search specification included only three whitefly species, since these three together account for 798 out of the total 811 insecticide resistance instances reported worldwide. Also, we used the term 'resistance', rather than 'insecticide resistance' as the search keyword since many of the article titles mention the name of the specific insecticides along with the term resistance, rather than the term 'insecticide resistance'. Though our analysis is entirely based on total studies retrieved, we also report the highly cited articles based on a citation threshold of 25 . Article citations are widely accepted as a yardstick of their impact, and in general, articles that are cited more than a hundred times are considered as highly cited. However, considering confinement of the topic 'insecticide resistance of whiteflies' to specific subject fields, and the data retrieval restricted to the last ten years for analysis, we considered citation number of 25 to be a good indicator of the article impact. We acknowledge the fact that articles may take time to accumulate citations, and hence we restrained from drawing any inference on the low citations of the articles published in the last three years of the study period. The data collected from WoS was analysed and mapped using VOSviewer. Network analysis was performed using the author keywords, authors, institutions and countries, and the link strengths were generated. For generating link strengths for network creation, the fractional counting approach was used as it helps visualize proper fieldnormalized results ${ }^{13}$. It also helps normalize the relative weights of links in a network, enabling better visualization of the network structure. Fractional counting gives equal weightage by dividing credit (into fractions) among the co-authors (authors, institutions, countries, etc.), which is not the case in the full counting approach. This approach helped us visualize the co-citation network of journals and authors, co-occurrence network of keywords and co-authorship networks of authors, institutions and countries.

\section{Results}

\section{Growth of publications and citations}

The search for research articles on insecticide resistance of whiteflies during the period 2010-20 indicated that the literature is enriched every year by the addition of valuable articles (Figure $1 a$ ). While the number of publications showed a gradual increase $(6 \%$ /year $)$, their citations had drastically increased (43\%/year; Figure $1 \mathrm{~b})$. A total of 1198 articles were identified with a total citation of 17,149 and each record was cited 14.31 times on average. The year 2020 witnessed the highest number of publications as well as citations. The sum of citations has consistently crossed the 1000 mark after 2014. The increasing trend in the number of publications and the sum of citations is a clear indication of the importance that whitefly insecticide resistance research is gaining momentum over the years. The highest share in whitefly resistance and related studies was occupied by the subject field of entomology (43.7\%), followed by agronomy (19.8\%), plant sciences (14.9\%), biochemistry and molecular biology $(9.2 \%)$, multidisciplinary science $(8.5 \%)$, and agriculture multidisciplinary $(7.8 \%)$ (Figure 2 ).
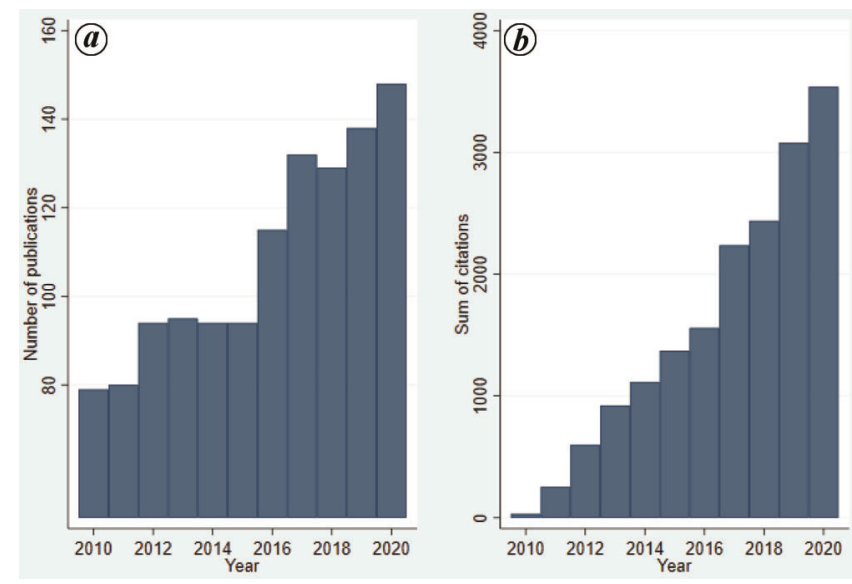

Figure 1. (a) Number of publications and (b) cumulative citations by year. 
Figure 3 shows the temporal distribution of highly cited articles on whitefly resistance. Results revealed that in the past decade, 198 studies on whitefly insecticide resistance were cited more than 25 times, and thus were included in the highly cited category. Interestingly, most studies were published in the first half between 2010 and 2015 (168). Together, these 198 studies were cited 10,609 times and there were more than 500 citations for each year from 2013. Though the citations of the highly cited articles showed an increasing trend in general, the number of highly cited articles showed a decreasing trend. This is primarily because the studies published in recent years have not been cited enough to be considered for inclusion in the analysis. No studies published from 2018 onwards could reach the threshold of 25 citations when the bibliometric analysis was done. This, however, is not an indication of the quality of studies published in recent years, since these articles may take more time to accumulate citations. Summing up, $25 \%$ of the articles published between 2010 and 2017 (keeping out the recent three years' publications) are included in the highly cited category.

\section{Preferred journals}

Most number of articles on insecticide resistance of whiteflies since 2010 have been published in Pest Management Science (Table 1). A total of 88 articles were published in the journal and they were cited 2184 times in total, which is also the highest number of citations that any journal has received on the topic. The other journals in the list with highest number of articles are Journal of

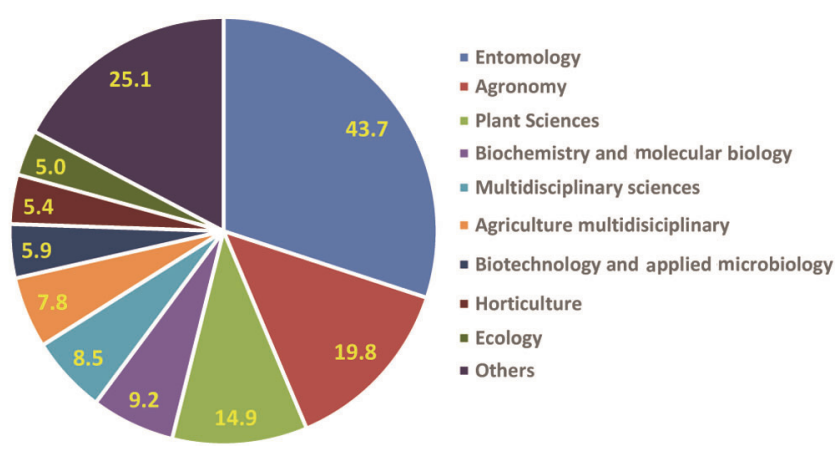

Figure 2. Subject wise share (\%) of publications on whitefly resistance.

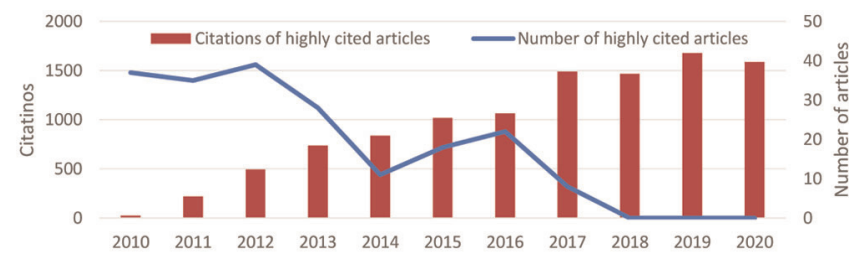

Figure 3. Highly cited articles and their citations by year.
Economic Entomology, PLOS ONE, Crop Protection and Pesticide Biochemistry and Physiology. The high impact factor (IF) of these journals is also an indicator of the quality of the research articles on the topic. The IF of the top 10 journals with the most number of publications on whitefly insecticide resistance was in the range 1.1374.578. In the list of journals with the highest number of citations, along with Pest Management Science and PLoS ONE, the Journal of Economic Entomology, Pesticide Biochemistry and Physiology, and BMC Genomics also appeared in the top position. Table 2 provides bibliometric details of the journals with highly cited articles (articles with more than 25 citations). Pest Management Science is the leading journal in terms of publications of highly cited articles on whitefly insecticide resistance. It encompasses 26 such articles on the topic during the period of our study. This journal publishes mainly on crop protection and pest control, and 'resistance of pests to pest management products and strategies' is one of the major topics covered. PLOS ONE comes next in the list with 17 highly cited articles. It is a peer-reviewed, open access journal that covers articles from multiple scientific disciplines. Pesticide Biochemistry and Physiology (13), Journal of Economic Entomology (10) and BMC Genomics (9) are the other top journals identified. While the total citations of highly cited articles are the highest for Pest Management Science (1599), BMC Genomics tops the table for citation per article (74.9). Except for PLOS ONE and Scientific Reports, all the other journals that appeared in the top 10 list with the highest number of highly cited articles are specific entomology, pesticide or genomics discipline-based. Importantly, more than 50\% of the articles with citation of 25 or more are published in a journal having an IF of at least 2.

Figure 4 depicts a co-citation analysis map to trace the relative number of co-citations for each journal. The map

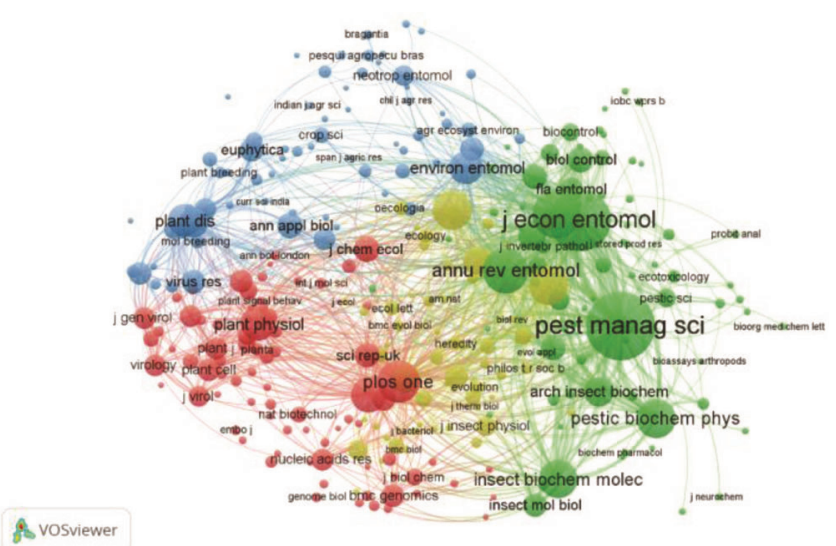

Figure 4. Co-citation network analysis of journals. Note: A threshold of 25 was applied which resulted in a total of 293 article sources. The bubble size refers to the citations received, while line thickness and colour refer to link strength and clustering respectively. 
Table 1. Top 10 journals with the highest number of articles and citations

\begin{tabular}{|c|c|c|c|}
\hline Journal and impact factor (IF) 2020 & $\begin{array}{l}\text { Number of } \\
\text { publications }\end{array}$ & Journal and IF 2020 & $\begin{array}{c}\text { Number of } \\
\text { citations }\end{array}$ \\
\hline Journals with the highest number of publications & & Journals with the highest number of citations & \\
\hline Pest Management Science (IF: 3.750) & 88 & Pest Management Science (IF: 3.750) & 2184 \\
\hline Journal of Economic Entomology (IF: 1.938) & 70 & PLOS ONE (IF: 2.740) & 993 \\
\hline PLOS ONE (IF: 2.740$)$ & 53 & Journal of Economic Entomology (IF: 1.938) & 976 \\
\hline Crop Protection (IF: 2.381) & 47 & Pesticide Biochemistry and Physiology (IF: 2.751) & 756 \\
\hline Pesticide Biochemistry and Physiology (IF: 2.751) & 44 & BMC Genomics (IF: 3.594) & 723 \\
\hline Scientific Reports (IF: 3.998) & 33 & Crop Protection (IF: 2.381) & 667 \\
\hline Frontiers in Plant Science (IF: 4.402) & 22 & Environmental Science and Pollution Research (IF: 3.056) & 529 \\
\hline Phytoparasitica (IF: 1.137$)$ & 21 & Scientific Reports (IF: 3.998$)$ & 481 \\
\hline Journal of Pest Science (IF: 4.578) & 19 & Journal of Pest Science (IF: 4.578) & 329 \\
\hline Bulletin of Entomological Research (IF: 1.814) & 16 & Journal of Agricultural and Food Chemistry (IF: 4.192) & 326 \\
\hline
\end{tabular}

Table 2. Top 10 journals with highly cited articles on whitefly resistance

\begin{tabular}{|c|c|c|c|c|}
\hline Journal & $\begin{array}{c}\text { Number of } \\
\text { articles (NA) }\end{array}$ & $\begin{array}{c}\text { Total citations } \\
\text { (NC) }\end{array}$ & $\mathrm{NC} / \mathrm{NA}$ & IF 2020 \\
\hline Pest Management Science & 26 & 1599 & 65.1 & 3.750 \\
\hline PLOS ONE & 17 & 715 & 42.1 & 2.740 \\
\hline Pesticide Biochemistry and Physiology & 13 & 497 & 38.2 & 2.751 \\
\hline Journal of Economic Entomology & 10 & 493 & 49.3 & 1.938 \\
\hline BMC Genomics & 9 & 674 & 74.9 & 3.594 \\
\hline Crop Protection & 8 & 349 & 43.6 & 2.381 \\
\hline Journal of Pest Science & 6 & 206 & 34.3 & 4.578 \\
\hline Scientific Reports & 6 & 210 & 35.0 & 3.998 \\
\hline Insect Biochemistry and Molecular Biology & 5 & 281 & 56.2 & 3.827 \\
\hline Biological Control & 4 & 125 & 31.3 & 2.754 \\
\hline
\end{tabular}

groups the journals according to their co-citation frequencies $^{14}$. The journals that are placed closer and represented by nodes with the same colour share greater similarities in the articles published ${ }^{15}$. The map was generated by setting a citation threshold of 25 , which enabled us to include 293 out of the total 6901 article sources. The map generated four distinct clusters, the biggest among which was made up of 83 items. This cluster represents the co-citation network of journals, including PLOS ONE (link strength 1082), Proceedings of the National Academy of Science USA (link strength 753), Plant Physiology (link strength 674), and other closely related ones. This cluster mainly consists of journals catering to multidisciplinary fields, as well as those dealing with genetics, biotechnology and molecular biology. The second cluster, which is made up of 80 items, represents the co-citation network of journals like Pest Management Science (link strength 2460), Journal of Economic Entomology (link strength 2073), Crop Protection (link strength 1319), Annual Review of Entomology (link strength 1203), etc. This cluster is formed around the entomology, toxicology, zoology and chemistry-based journals. The third cluster is made up of 69 items (mainly plant pathology and virology-based), and Plant Disease (link strength 336) is the most important journal around which this cluster is formed. The final and smallest cluster, containing 61 journals, is formed around Entomolo- gia Experimentalis et Applicata (link strength 901), and this cluster provides the network of ecology and environment-based journals.

\section{Influential articles and authors}

Identifying the most influential articles and authors on a topic is important in bibliometric analysis. Thus, we performed a citation analysis to identify the most influential articles. The logic being that the articles which have received the most citations are the ones having the biggest influence on the subject. Table 3 presents the top 10 articles along with their citation numbers. The most influential article published after 2010 is authored by Simon-Delso et al. (Table 3). This article published in 2015 , could attract 529 citations in total, that tallies to an average of 88 citations per year, when the analysis was done. The article describes the popularity and modes of action of neonicotinoids and fipronil, emphasizing on the recent instances of whitefly resistance development against neonicotinoids. The article by Wang et al. is identified as the next most influential one. It received a total of 307 citations, and presented a cost-effective and rapid method for transcriptome and DGE analysis using Illumina sequencing technology, which has a huge potential to accelerate whitefly resistance research. Characterization of the transcriptome of whitefly B. tabaci can serve as a 
Table 3. Top-10 influential articles on whitefly resistance

\begin{tabular}{|c|c|}
\hline Articles & Citations \\
\hline $\begin{array}{l}\text { Simon-Delso, N. et al., Systemic insecticides (neonicotinoids and fipronil): trends, uses, } \\
\text { mode of action and metabolites. Environ. Sci. Pollut. Res., 2015, 22(1), 5-34. }\end{array}$ & 529 \\
\hline $\begin{array}{l}\text { Wang, X. W., Luan, J. B., Li, J. M., Bao, Y. Y., Zhang, C. X. and Liu, S. S., De novo } \\
\text { characterization of a whitefly transcriptome and analysis of its gene expression during } \\
\text { development. BMC Genomics, 2010, 11(1), 1-11. }\end{array}$ & 307 \\
\hline $\begin{array}{l}\text { Puinean, A. M. et al., Amplification of a cytochrome } \mathrm{P} 450 \text { gene is associated with resistance } \\
\text { to neonicotinoid insecticides in the aphid Myzus persicae. PLOS Genetics, 2010, 6(6), } \\
\text { e1000999. }\end{array}$ & 257 \\
\hline $\begin{array}{l}\text { Zhu, Y. et al., Discovery and characterization of sulfoxaflor, a novel insecticide targeting } \\
\text { sap-feeding pests. J. Agric. Food Chem., 2011, 59(7), 2950-2957. }\end{array}$ & 195 \\
\hline $\begin{array}{l}\text { Tiwari, S., Mann, R. S., Rogers, M. E. and Stelinski, L. L., Insecticide resistance in field } \\
\text { populations of Asian citrus psyllid in Florida. Pest Manag. Sci., 2011, 67(10), 1258-1268. }\end{array}$ & 186 \\
\hline $\begin{array}{l}\text { Mann, R. S., Ali, J. G., Hermann, S. L., Tiwari, S., Pelz-Stelinski, K. S., Alborn, H. T. and } \\
\text { Stelinski, L. L., Induced release of a plant-defense volatile 'deceptively' attracts insect } \\
\text { vectors to plants infected with a bacterial pathogen. PLOS Pathog., 2012, 8(3), e1002610. }\end{array}$ & 154 \\
\hline $\begin{array}{l}\text { Gilbertson, R. L., Batuman, O., Webster, C. G. and Adkins, S., Role of the insect supervec- } \\
\text { tors Bemisia tabaci and Frankliniella occidentalis in the emergence and global spread of } \\
\text { plant viruses. Ann. Rev. Virol., 2015, 2(1), 67-93. }\end{array}$ & 130 \\
\hline $\begin{array}{l}\text { Babcock, J. M. et al., Biological characterization of sulfoxaflor, a novel insecticide. Pest } \\
\text { Manage. Sci., 2011, 67(3), 328-334. }\end{array}$ & 129 \\
\hline $\begin{array}{l}\text { Wang, Z., Yan, H., Yang, Y. and Wu, Y., Biotype and insecticide resistance status of the } \\
\text { whitefly Bemisia tabaci from China. Pest Manage. Sci., 2010, 66(12), 1360-1366. }\end{array}$ & 119 \\
\hline $\begin{array}{l}\text { Luo, C., Jones, C. M., Devine, G., Zhang, F., Denholm, I. and Gorman, K., Insecticide resis- } \\
\text { tance in Bemisia tabaci biotype Q (Hemiptera: Aleyrodidae) from China. Crop Prot., } \\
\text { 2010, 29(5), 429-434. }\end{array}$ & 116 \\
\hline
\end{tabular}

Table 4. Top 10 authors with respect to documents published and citations received

\begin{tabular}{lclc}
\hline Authors & Documents & \multicolumn{1}{c}{ Authors } & Citations \\
\hline Zhang Youjun & 50 & Denholm Ian & 981 \\
Wang Shaoli & 43 & Liu Shu-Sheng & 875 \\
Wu Qingjun & 41 & Xie Wen & 802 \\
Xie Wen & 40 & Zhang Youjun & 734 \\
Wan Fang-hao & 26 & Wang Shaoli & 718 \\
Liu Shu-Sheng & 22 & Gorman Kevin & 685 \\
Luo Chen & 20 & Wu Qingjun & 663 \\
Baldin Edson & 19 & Wang Xiao-Wei & 608 \\
Chu Dong & 19 & Williamson Martin & 608 \\
Pan Huipeng & 19 & Amaral Rogers & 529 \\
\hline
\end{tabular}

base for most of the genomic studies and thus increase the importance of this research work. Most of the other articles included in Table 3 are also highly cited and deal with important aspects like the effect of gene amplification, introduction of newer insecticides, role of whitefly as a super vector for virus spreading, status of insecticide resistance of different populations and biotypes, etc. all in relation with resistance.

Zhang Youjun, Wang Shaoli and Wu Qingjun are the three authors identified with the highest number of publications, and Denholm Ian, Liu Shu-Sheng and Xie Wen are the top-cited authors on insecticide resistance of whitefly (Table 4). Youjun works with the Chinese Academy of Agricultural Sciences. He has published 50 articles on the topic that have been cited 734 times at the time of this analysis. Shu-Sheng is a Professor of entomology at the
Institute of Insect Sciences of the Zhejiang University, China. He is one of the most influential authors in research on insecticide resistance of whiteflies since 2010. He has published 22 articles since 2010 that were cited 875 times when we collected the data. Denholm Ian (University of Hertfordshire, United Kingdom) is the author with the highest number of citations for his work during the study period. Xie Wen, Gorman Kevin, and Wang Xiao-Wei have also contributed immensely to the literature with their publications.

Figure 5 presents the author co-citation network map. The analysis selected 160 authors from a total of 19,835 based on a threshold citation level of 40. The map has grouped the authors into four different clusters based on their co-citation information. The co-citation map indicates the relatedness of the articles published by the authors in the same clusters, based on the extent to which these authors are cited together by other authors. The first cluster (red) is the biggest one consisting of 50 authors. Nauen, R., Roditakis, E. and Ahmad, M. are the leading authors in this cluster with citation figures of 472, 215 and 182, and link strength values (based on fractional counting) of 431, 201 and 160 respectively. The second cluster made up of 46 authors is represented in green colour. De Barro, P. J. and Horowitz, A. R. are the top authors identified in this cluster. De Barro received a link strength of 439 , which is the highest among all the authors included in the map, while Horowitz's link strength value was 386 . In each cluster, one can identify stand-out authors, around whom all other authors are 
placed. For example, we identified some such authors in different clusters, viz. Byrne, D. N., Nombela, G., Lapidot, M., Polston, J. E., etc. The point to be considered from the co-citation map is that though all the authors appearing in the map published on insecticide resistance of whiteflies, the works of authors in the same clusters are more related by nature (hence grouped into a cluster) and utility to the other researchers.

\section{Prevalent topics of research}

The priorities and interests of researchers on whitefly insecticide resistance and related studies were identified using a co-occurrence network of the most frequently used author keywords. According to the analysis, Bemisia tabaci was the keyword that attracted the highest occurrences (292). Other important keywords were whitefly (132), resistance (87), insecticide resistance (76), tomato (54), begomovirus (52), imidacloprid (44), biological control (42), host plant resistance (36) and neonicotinoids (30). Among all the author keywords, Bemisia tabaci had the highest link strength (169), followed by whitefly (78). The author keywords Bemisia tabaci and whitefly were both highly connected to insecticide resistance, resistance, host plant resistance and biological control (Figure 6). A total of six author keyword clusters were identified before mapping. The first cluster was made up of 10 keywords, including Bemisia tabaci, insecticide resistance, cross-resistance and insecticides like neonicotinoids, imidacloprid, thiamethoxam, etc. The second cluster (seven keywords) contained keywords like host plant resistance and related terms like antibiosis, antixenosis, etc. The third cluster consisted of whitefly, resistance, insecticide, toxicity, etc. and the fourth cluster contained biological control and related author keywords. The fifth and sixth clusters dealt with keywords on virus resistance/disease and the acids responsible for host plant resistance respectively. From the analysis of recent literature, we found that insecticide resistance is highly related to the species $B$. tabaci. Regarding insecticide resistance,

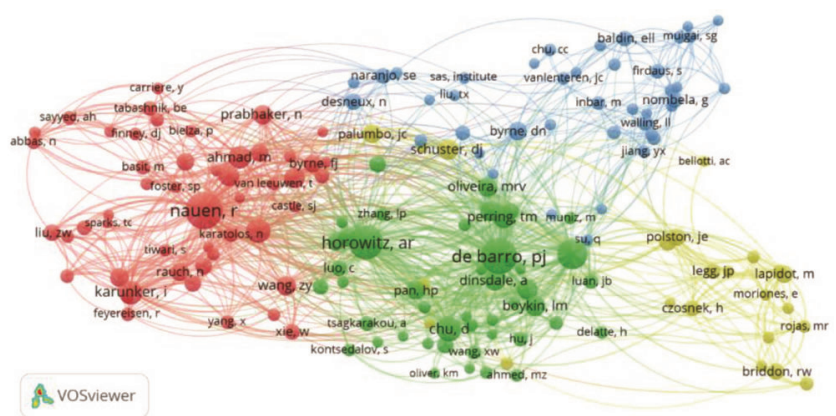

Figure 5. Co-citation network analysis of authors. Note: A threshold of 40 was applied which resulted in a total of 160 authors. The bubble size refers to the citations received, while line thickness and colour refer to link strength and clustering respectively. the data accessed through APRD also document the same with 664 resistance cases of $B$. tabaci against 61 different active substances across the world ${ }^{4}$. Insecticide resistance in $B$. tabaci has also been reported in new chemicals like cyantraniliprole ${ }^{16}$ and flupyradifurone ${ }^{17}$.

\section{Predominant countries and institutions}

According to the link strength values generated based on the fractional counting approach, USA is the most active country (link strength 120). This suggests that USA has the largest number of collaborative research articles on the topic with other countries, and hence can be considered as the leader in this field. The link strength generated for China is also very high (104). China, USA, Brazil, Pakistan and India are the leading countries in the world in terms of the total number of publications on the topic during the study period (2010-20). China published 327 documents that were cited the most (5170), followed by USA ( 239 publications and 5028 citations). The state of collaborations between countries as given in Figure 7, suggest a total of five clusters that were mapped. The first cluster is made up of five European countries, including Spain, Germany, The Netherlands, Belgium and Greece; the second cluster is that of England and collaborators. The third cluster is made around China and the fourth of Asian countries, including India and Pakistan. The fifth and the final cluster is formed around USA with its close collaborators like Brazil and South Korea.

The Chinese Academy of Agricultural Sciences (link strength 52), Beijing Academy of Agriculture and Forestry Sciences (link strength 22), China; University of Florida (link strength 21), University of Arizona (link strength 19), USA, and the Agricultural Research Organization of Israel (link strength 19) were the leading

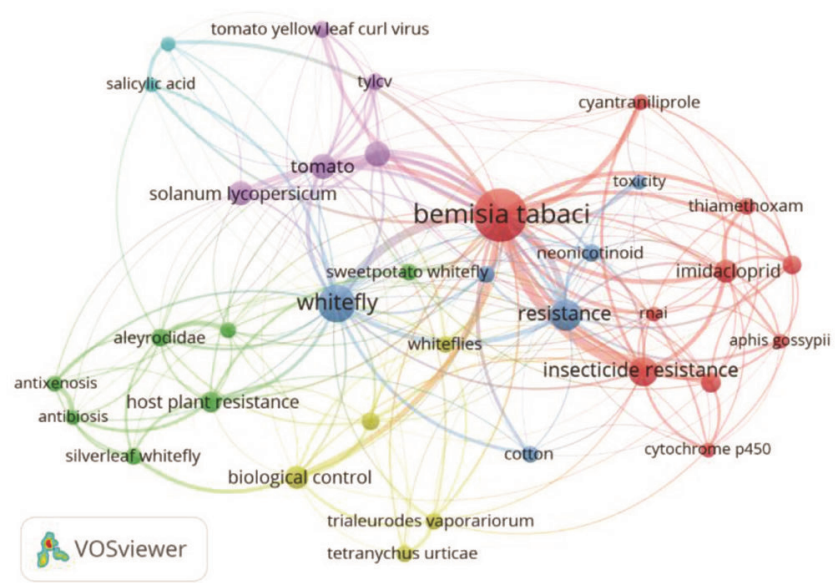

Figure 6. Co-occurrence network of the most frequently used author keywords. Note: A threshold of 15 was applied which resulted in a total of 35 keywords. The bubble size refers to the total number of articles, while line thickness and colour refer to link strength and clustering respectively.

CURRENT SCIENCE, VOL. 120, NO. 9, 10 MAY 2021 
institutions in the world in terms of their collaborative research work with other organizations. More than half of the topmost productive institutions on whitefly resistance publications were from USA and China. These organizations also top the chart in terms of the number of documents as well as the number of citations. Figure 8 clearly depicts the role that local institutions play in placing their respective countries in top positions in research in the field. The first cluster is made up of the United States Department of Agriculture University of California, USA, and the collaborating institutions (Indian Agricultural Research Institute and Punjab Agricultural University also appear in this cluster). The second cluster is around the Chinese Academy of Agricultural Sciences, in which the University of Kentucky, USA, also appears. The third and fourth clusters are formed around the University of Florida and the Agricultural Research Organization of Israel respectively. Beijing Academy of Agricultural and Forestry Science, University of Faisalabad, Pakistan, Nanjing University, China are other influential organizations working on this topic.

\section{Indian literature}

A total of 91 articles were published on the topic from India during 2010-20, which were cited 730 times (average citation of 8.02 per article). PLOS ONE was the leading journal identified in terms of the number of documents as well as citations. Scientific Reports, BMC Genomics and Phytoparasitica were the other top-cited journals. In terms of the number of documents published, Indian Journal of Agricultural Sciences followed PLOS $O N E$. The Indian Agricultural Research Institute (IARI), New Delhi was the lead institution with the highest number of publications (19) and citations (296). Though Punjab Agricultural University (18), Indian Institute of

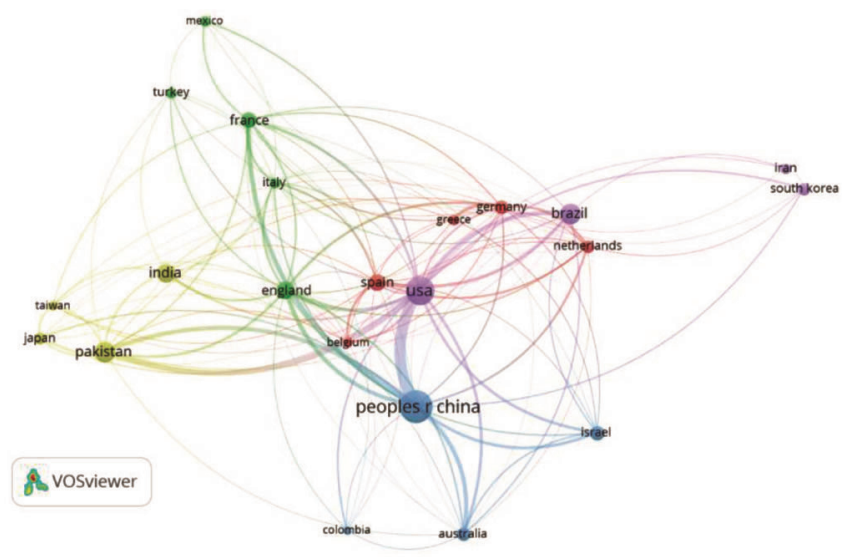

Figure 7. Co-authorship network of countries. Note: A threshold of 15 was applied, which resulted in a total of 22 countries. The bubble size refers to the total number of articles, while line thickness and colour refer to link strength and clustering respectively.
Horticulture Sciences (7) and Tamil Nadu Agricultural University (7) were the other organizations in the list, the National Botanical Research Institute and Banaras Hindu University appeared in the top-cited institutions after IARI. Kranthi K. R., Varma A. and Upadhyay S. K. were the lead authors identified in terms of citations. 'Enhanced Whitefly Resistance in Transgenic Tobacco Plants Expressing Double Stranded RNA of v-ATPase A Gene' authored by Thakur et al. in PLOS ONE, 'Comparative transcriptome analysis of Gossypium hirsutum L. in response to sap sucking insects: aphid and whitefly by Dubey et al. in BMC Genomics and 'Insecticide resistance status in the whitefly, Bemisia tabaci genetic groups Asia-I, Asia-II-1 and Asia-II-7 on the Indian subcontinent' by Naveen et al., published in Scientific Reports were the highest cited articles.

\section{Study limitations}

Our analysis is based exclusively on the literature retrieved from WoS in December 2020 and is solely based on the keywords mentioned in the publications. We accept the fact that the literature retrieved may not be exhaustive, since the use of different databases like Scopus or Google Scholar would have resulted in a different collection of research articles. The citation figures may also vary across these databases. The findings of this study must hence be interpreted cautiously considering the continuous evolution of research evidence on the topic. Among the different bibliometric approaches, we have used fractional counting to give equal weightage to the entities involved in research articles. Though equal weightage is an advantage of this approach, there are disadvantages as well that need to be acknowledged. In this study, we have solely used the citation numbers for identifying influential articles, though we acknowledge that a normalized score of citations using the journal IF and age of the articles would have provided a different result.

\section{Summary}

We have performed a prototype analysis of the global literature on insecticide resistance of whiteflies published during the period 2010-20, as indexed in WoS (as of December 2020). The study considered a total of 1198 publications having 17,149 citations. Analysis was done using bibliometric parameters and networks were visualized using VOSviewer.

An increasing trend of publication growth and their corresponding citations over time signify the importance of this research topic. Among the leading countries, were USA and China dominated by the institutions like the Chinese Academy of Agricultural Sciences, University of Florida, Beijing Academy of Agriculture and Forestry Sciences, University of Arizona. Research priority was 


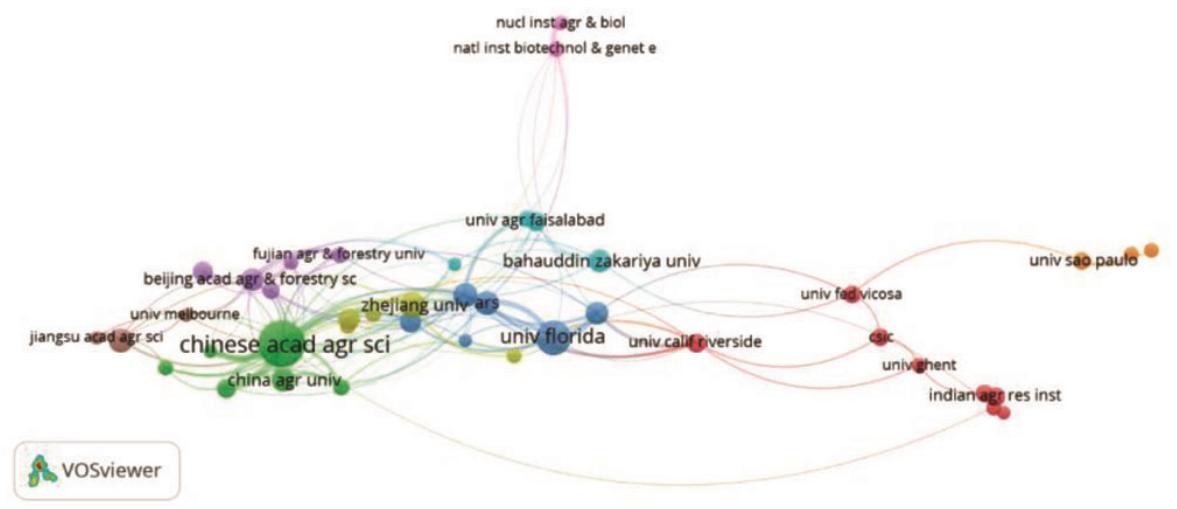

Figure 8. Co-authorship network of organizations. Note: A threshold of 10 was applied, which resulted in a total of 44 organization. The bubble size refers to the total number of articles, while line thickness and colour refer to link strength and clustering respectively.

distributed among topics like insecticide resistance of different whitefly species like $B$. tabaci, resistance against different insecticide groups, biological control of whitefly, host plant resistance, etc.

This study can be used to identify prolific researchers, profound journals, predominating countries/institutions and prevalent areas of research in this field. The findings can act as a ready reference for researchers and serve them with useful information to formulate strategies for future studies. Researchers may find their peers, and funding bodies could identify the targeted authors/ institutions for possible investments.

1. Sundararaj, R. and Dubey, A., Species diversity of whiteflies (Hemiptera: Aleyrodidae) in Western Ghats, India. In Invertebrate Diversity and Conservation in the Western Ghats (eds Priyadarsanan, D. et al.), Ashoka Trust for Research in Ecology and the Environment, Bengaluru, 2019, pp. 225-234.

2. Anjum, H. and Ahmed, S. I., An updated and consolidated review on Indian aleyrodids fauna (Hemiptera: Aleyrodidae: Insecta) along with their host plant families and distributional records. Rec. Zool. Surv. India, 2019, 119(4), 381-417.

3. Martin, J. H. and Mound, L. A., An annotated check list of the world's whiteflies (Insecta: Hemiptera: Aleyrodidae). Zootaxa, 2007, 1492(1), 1-84.

4. Taquet, A., Delatte, H., Barrès, B., Simiand, C., Grondin, M. and Jourdan-Pineau, H., Insecticide resistance and fitness cost in Bemisia tabaci (Hemiptera: Aleyrodidae) invasive and resident species in La Réunion Island. Pest Manage. Sci., 2020, 76(4), $1235-1244$.

5. Chaubey, R., Andrew, R. J., Naveen, N. C., Meshram, N. M. and Ramamurthy, V. V., Bemisia tabaci (Gennadius) (Hemiptera: Aleyrodidae) species complex from cotton and leucaena: a comparative study of morphometrics. Entomol. News, 2015, 125(3), 163-173.

6. Oliveira, M. R. V., Henneberry, T. J. and Anderson, P., History, current status, and collaborative research projects for Bemisia tabaci. Crop Prot., 2001, 20(9), 709-723.
7. Dubey, A. K. and Ko, C. C., Whitefly (Aleyrodidae) host plants list from India. Orient. Insects, 2008, 42(1), 49-102.

8. Pym, A. et al., Host plant adaptation in the polyphagous whitefly, Trialeurodes vaporariorum, is associated with transcriptional plasticity and altered sensitivity to insecticides. BMC Genomics, 2019, 20(1), 996.

9. Horowitz, A. R. and Ishaaya, I., Dynamics of biotypes B and Q of the whitefly Bemisia tabaci and its impact on insecticide resistance. Pest Manage. Sci., 2014, 70(10), 1568-1572.

10. Arthropod Pesticide Resistance Database, Michigan State University, USA; https://www.pesticideresistance.org/ (cited 30 October 2020).

11. Naveen, N. C. et al., Insecticide resistance status in the whitefly, Bemisia tabaci genetic groups Asia-I, Asia-II-1 and Asia-II-7 on the Indian subcontinent. Sci. Rep., 2017, 7(1), 40634.

12. Fahimnia, B., Sarkis, J. and Davarzani, H., Green supply chain management: a review and bibliometric analysis. Int. J. Prod. Econ., 2015, 162, 101-114.

13. Zhang, X., Estoque, R. C., Xie, H., Murayama, Y. and Ranagalage, M., Bibliometric analysis of highly cited articles on ecosystem services. PLoS ONE, 2019, 14(2), e0210707.

14. Zupic, I. and Čater, T., Bibliometric methods in management and organization. Org. Res. Methods, 2015, 18(3), 429-472.

15. Merigó, J. M., Cancino, C. A., Coronado, F. and Urbano, D., Academic research in innovation: a country analysis. Scientometrics, 2016, 108(2), 559-593.

16. Wang, R., Wang, J., Che, W., Sun, Y., Li, W. and Luo, C., Characterization of field-evolved resistance to cyantraniliprole in Bemisia tabaci MED from China. J. Integr. Agric., 2019, 18(11), 2571-2578.

17. Wang, R., Wang, J., Che, W., Fang, Y. and Luo, C., Baseline susceptibility and biochemical mechanism of resistance to flupyradifurone in Bemisia tabaci. Crop Prot., 2020, 132, 105132.

Received 4 November 2020; revised accepted 10 February 2021

doi: $10.18520 / \mathrm{cs} / \mathrm{v} 120 / \mathrm{i} 9 / 1433-1440$ 